\title{
Novel mode of postembryonic development in Ammothea genus (Pycnogonida: Ammotheidae) from Antarctic waters
}

\author{
ESPERANZA CANO and PABLO J. LÓPEZ-GONZÁLEZ \\ Biodiversidad y Ecología de Invertebrados Marinos, Departamento de Fisiología y Zoología, Facultad de Biología, \\ Universidad de Sevilla, Avda. Reina Mercedes 6, 41012-Sevilla, Spain. E-mail: ecano@us.es
}

\begin{abstract}
SUMMARY: In this paper the postembryonic development of Ammothea glacialis (family Ammotheidae) is described. The studied material was collected during the Italica XIX cruise to Victoria Land, Ross Sea, Antarctica. The external morphology of three larval instars is described and illustrated. The development of A. glacialis has the following characteristics: (1) protonymphon hatch from the eggs; (2) the larvae have yolk reserves and relatively large size $(0.7 \mathrm{~mm}$ in length); (3) the larvae remain on the ovigerous legs of males during several moults; (4) the larvae have reduced larval II-III appendages and the spinning apparatus is absent; (5) the development of walking legs is sequential. This development is compared with those previously known, especially with Propallene longiceps and Nymphon grossipes.
\end{abstract}

Keywords: Pycnogonida, Ammotheidae, Ammothea, postembryonic development, protonymphon.

\begin{abstract}
RESUMEN: Nuevo modo de deSArrollo postembrionario en el género Ammothea (Pycnogonida: Ammotheidae) PROCEDENTE DE AGUAS ANTÁrTICAS. - En este trabajo se describe el desarrollo postembrionario de Ammothea glacialis (familia Ammotheidae). El material estudiado fue recolectado durante el crucero Itálica XIX a Tierra Victoria, en el mar de Ross, Antártida. Se describe e ilustra la morfología externa de tres estadios larvarios. El desarrollo de A. glacialis se caracteriza por: (1) la larva eclosiona como protonymphon; (2) la larva es de tamaño relativo grande (0.7 mm de longitud) y con reservas de vitelo; (3) la larva permanece en los ovígeros del macho durante varias mudas; (4) la larva presenta los apéndices larvarios II y III reducidos y el "spinning apparatus" está ausente; (5) el desarrollo de las patas es secuencial. Este desarrollo es comparado con otros desarrollos postembrionarios previamente conocidos, especialmente con los de Propallene longiceps and Nymphon grossipes.
\end{abstract}

Palabras clave: Pycnogonida, Ammotheidae, Ammothea, desarrollo postembrionario, protonymphon.

\section{INTRODUCTION}

The pycnogonids, or sea spiders, which can be found in all marine habitats ranging from the intertidal zone to abyssal depths, are distributed worldwide, and range in size from less than $1 \mathrm{~mm}$ to over $70 \mathrm{~cm}$ in leg span (Hedgpeth, 1947; Arnaud and Bamber, 1987).

In pycnogonids a series of courtship and mating behaviours have been observed during which the fe- male lays the eggs and transfers them to the male's oviger appendages. Fertilisation is external: the male fertilises the eggs once they have been placed into his care, and then glues them to the oviger, forming compact egg masses. He carries the eggs around until they hatch, but in several cases he continues to carry the larvae after hatching during part of their postlarval development (Wilhelm et al., 1997; Bain and Govedich, 2004). The eggs hatch usually as "protonymphons" (a form with only three pairs 
of larval appendages), although in some cases the eggs directly hatch as postlarval stage because protonymphons evolute completely into the egg shell (Bamber, 2007).

Data on larvae are known for about 70 species (Bain, 2003a) but morphological distinctions are present. Bain (2003a) divided the postembryonic development in pycnogonids into four different types: (1) Typical Protonymphon, the most common developmental type (Okuda, 1940; Bain, 2003a; Vilpoux and Waloszek, 2003; Bogomolova and Malakhov, 2003, 2004; Gillespie and Bain, 2006); (2) Encysted Larva (Staples and Watson, 1987; Bain, 2003a; Lovely, 2005; Bogomolova and Malakhov, 2003); (3) Atypical Protonymphon (Ohshima, 1933; Bain, 2003a); and (4) Attaching Larva (Nakamura, 1981; Bain, 2003a, b; Bogomolova and Malakhov, 2003, 2004). After a fifth postembryonic development, Lecithotrophic Protonymphon was suggested (Bogomolova and Malakhov, 2003, 2004, 2006; Bogomolova, 2007). As cited above, this terminology (named for postlarval development) has been widely used by subsequent authors in describing the postembryonic development of several species. However, the use of the terms "protonymphon" and "larva" to describe postlarval developmental patterns should be revised in order to avoid confusion and to clearly delimitate the terminology dedicated to larval and postlarval features, respectively.

Larval morphology may also be an important source of taxonomic characters, although most of the work still remains to be done on those groups in which the larva is known (Bogomolova and Malakhov, 2003, 2004, 2006; Bogomolova, 2007; Bouvier, 1923; Meinert, 1899). For some families, postembryonic development is still unknown and our scarce knowledge concerning the internal relationships in these groups can only be based on the morphology of the adult forms. This is, for example, the case of the families Rhynchothoracidae and Colossendeidae (Cano and López-González, 2007a). In these cases, studies based on molecular taxonomy such as that carried out by Mahon et al. (2008) on a set of Nymphon species can be of special interest in finding a solution to these problems.

This paper records a novel larval development for the Ammothea genus (family Ammotheidae). Each larval instar found on the male ovigerous legs of Ammothea glacialis (Hodgson, 1907) is described and illustrated, and a comparative discussion about the morphology observed among other previously published studies of larval postembryonic development is provided.

\section{MATERIAL AND METHODS}

A male specimen of Ammothea glacialis, carrying more than 400 larvae, was collected off Victoria Land coast (Victoria Land Transect Cruise 2004, N/O Italica XIX, stn. Hin-3, Cape Hallet, $72^{\circ} 17^{\prime} .0 \mathrm{~S}$ $170^{\circ} 13^{\prime} .1 \mathrm{E}, 316-328 \mathrm{~m}, 16$ February 2004) with the aid of a small Agassiz trawl. The specimen was sorted, fixed in $10 \%$ buffered formalin in seawater and then transferred to $70 \%$ ethanol. This specimen, cited in Cano and López-González (2007b: 439) with the deposit code BEIM(CRP-1), is now deposited for future consultation in the Museo Nazionalle dell'Antartide, Genova (MNA) with the deposit code MNA 1200 (male specimen), MNA 1201 (larvae of the third larval stage) and MNA 1202 (larvae of the fourth larval stage).

Different specimens of each larva instar were prepared for SEM study, dehydrated in an alcoholic series from $70 \%$ to $100 \%$ subsequently critical-pointdried, mounted on stubs, coated with gold-palladium and observed with a Philip XL30 SEM.

\section{RESULTS}

\section{Second instar larvae $(\mathrm{n}=1)$ (Figs. $1 ; 2 ; 4 \mathrm{~A})$}

The earliest larva instar found is a small $(0.7 \mathrm{~mm}$ in length) unsegmented oval-shaped larva. It has chelifores, proboscis, two pairs of larval appendages and a primordial of pair I of the walking legs. Eyes are not present and the anus is absent.

The body surface is practically smooth, with scattered multifurcated sensilla. Ventrally, two pairs of pores of unknown origin or function are located at the centre of the inter-limb area.

The cylindrical proboscis, with a trimeric mouth (Fig. 6A) and the chelifores are present at the anterior part of the body. The proboscis is as long as the chelifores. The basal articles of the chelifores is slightly shorter than the chelae; the immovable finger bears a spine on the outer surface; the fingers are curved at the tip and they are smooth on the inner surface (Fig. 6E); slit-like pores are present on the dorsolateral surface of the basal article. 
LATERAL

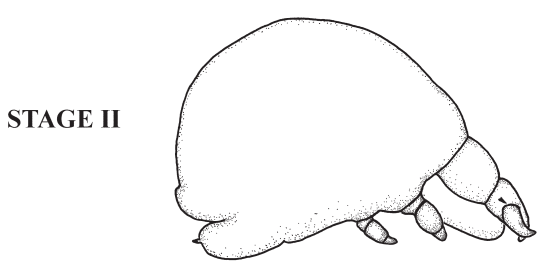

VENTRAL

DORSAL
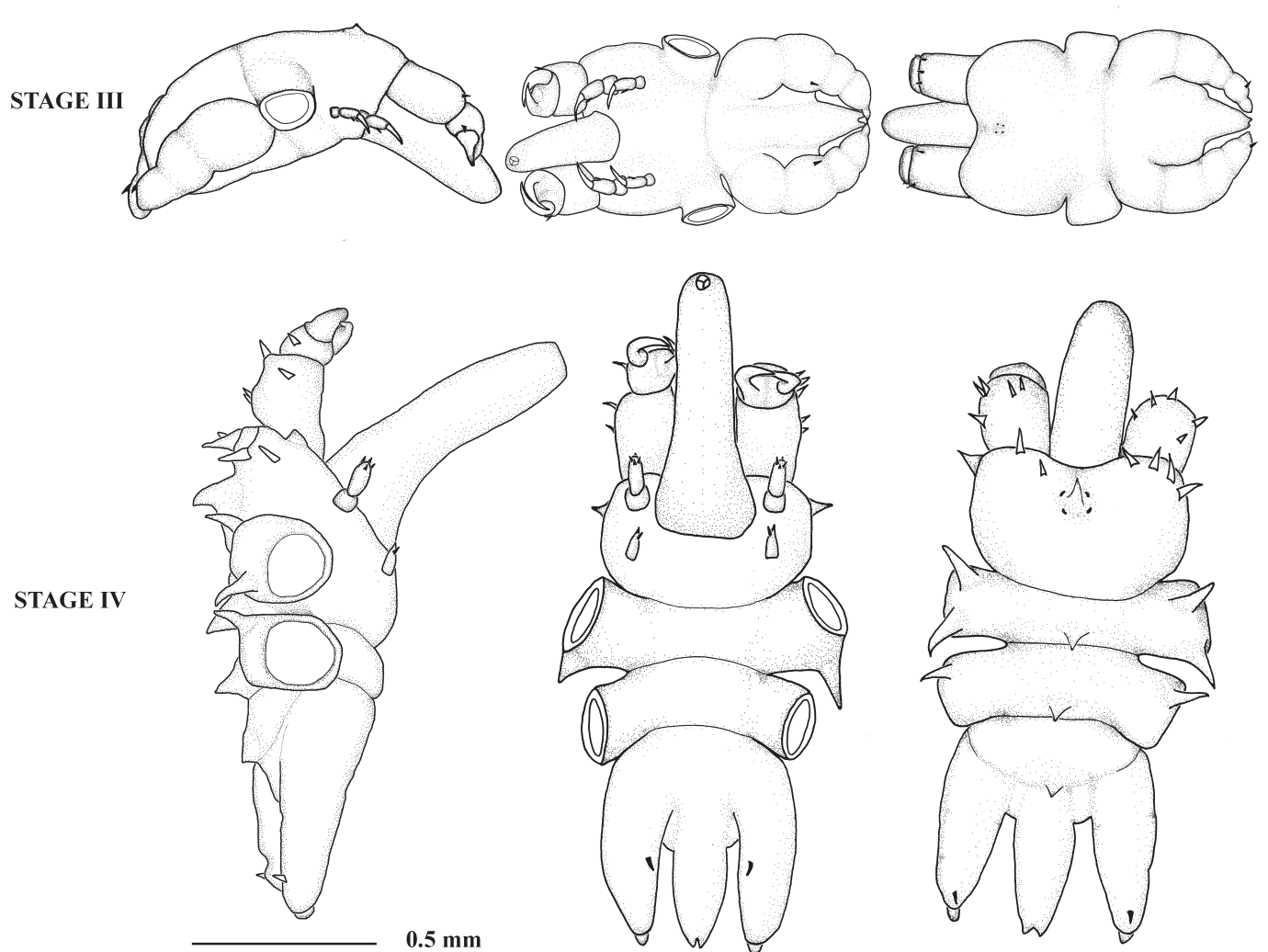
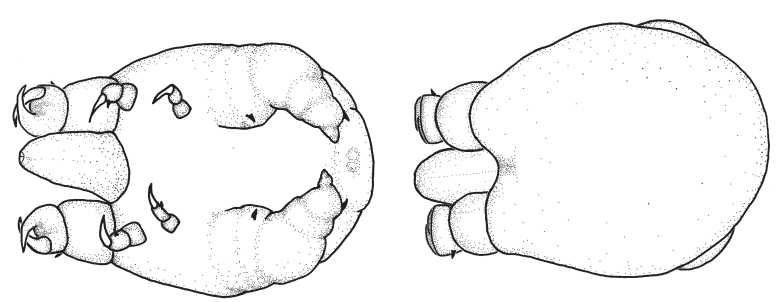

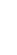
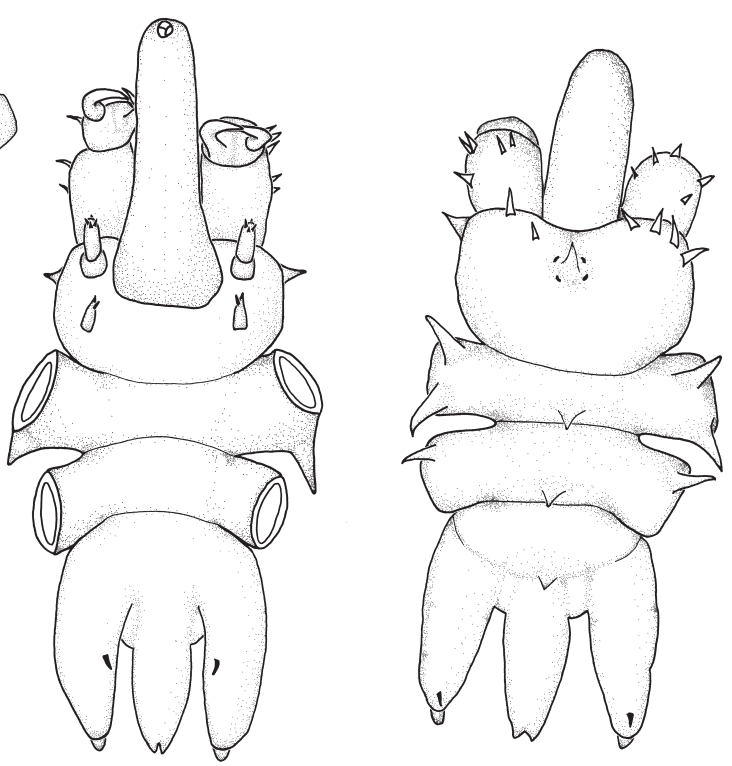

FIG. 1. - Larvae of Ammothea glacialis (Hodgson, 1907). Lateral, ventral and dorsal view of the three instar larvae (which is developing on the appendages of the male)

Pairs II and III of the larval appendages have three articles, with the same structure. The first segment is shorter than the second one; the terminal article is claw-like, longer than the second article. The second article of appendages II and III carry a spine on the inner surface.

The limb buds of the first pair of walking legs are unarticulated and have a spine on the outer posterior surface and on the internal anterior surface proximally.

Third instar larvae $(\mathrm{n}=339)$

(Figs. 1; 2; 3; 4B; 5A, B, C)

In this instar (about $0.85 \mathrm{~mm}$ in length, based on 10 specimens) the body is enlarged, the first walking legs are developed, and the limb buds of the second walking legs appear, as do incipient limb buds of the third walking legs. The ocular tubercle is distinct, but not completely developed. Four primordial eyes can be seen due to the transparency of the cuticle.

The body surface is practically smooth, with scattered multifurcated sensilla. Articulation between the first and second leg article is distinctly delimited. Ventrally, two pairs of pores of unknown origin or function are located at the centre of the second and third walking leg rudiments.

The proboscis is longer than the chelifores and is directed downwards. The basal article of the chelifores is longer than the chelae and has two spines on the distal part; the immovable finger bears a spine on the outer surface; the fingers are curved at the tip 


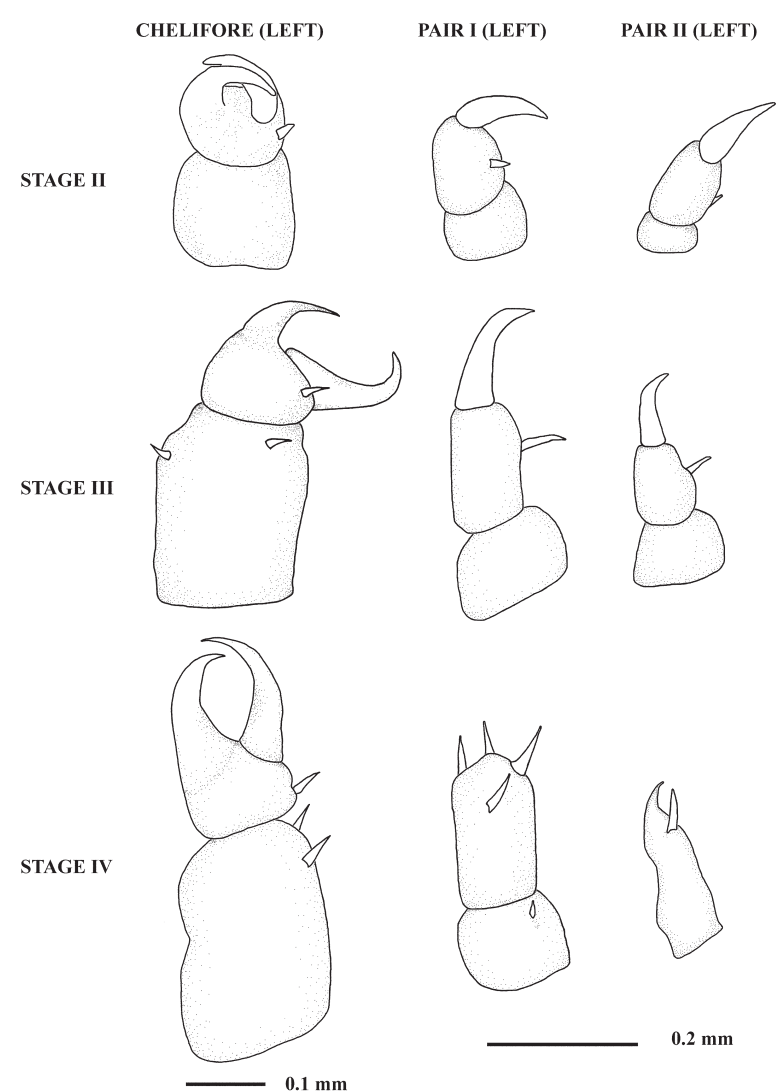

FIG. 2. - Larvae of Ammothea glacialis (Hodgson, 1907). Chelifores and larval II-III appendages of the three instar larvae.

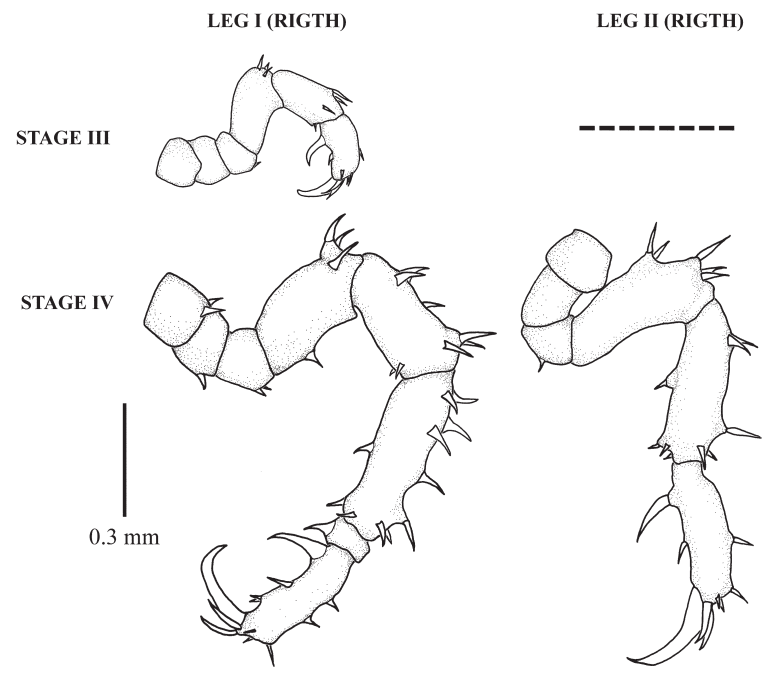

FIG. 3. - Larvae of Ammothea glacialis (Hodgson, 1907). Walking legs of the third and fourth instar larvae.

and smooth on the internal surface; slit-like pores are present on the outer lateral surfaces of the chelae bases and on the dorsolateral surface of the basal article distally (Fig. 6F; G).

Pairs II and III of the larval appendages are similar to those described for the second instar.
The first pair of walking legs has six articles. Coxa I to III short, the last one with a short ventro-distal spine; femur and tibia I with three dorsodistal spines, tibia I with an additional ventro-distal spine; propodus with three dorso-distal spines, one dorso-medial and a heel spine more developed than the single sole spine; main claw and auxiliary claws are present; a pore of unknown origin or function is located on the propodus close to the auxiliary claw bases.

The limb buds of the second pair of walking legs are similar to the first pair of the second instar.

The abdomen has now formed and is located between the pair of limb buds. The anus is closed (Fig. 6B).

Fourth instar larvae $(\mathrm{n}=105)$

(Figs. 1; 2; 3; 4C; 5D, E)

This instar (about $1.3 \mathrm{~mm}$ in length, based on 10 specimens) differs from the third instar in the following ways: the body is larger, the second walking legs are developed, the limb buds of the third walking legs and incipient limb buds of the fourth walking legs appear; and the ocular tubercle is more developed.

The body surface is practically smooth, with scattered multifurcated sensilla (Fig. 6H). On the dorsal surface, close to the insertion of the chelifores, 24 spines are present; asymmetry in the number of spines on the left and right side of a determined specimen has frequently been observed when studying the different individuals examined (see Fig. 5E); a lateral process of the first leg with two spines (anterior and posterior), a lateral process of the second leg with one anterior spine; first, second and third leg segment with dorso-medial tubercle, with distinct intersegmental suture-line traces between cephalic, first and second walking leg segments. Ventrally, two pairs of pores of unknown origin or function are located in the centre of the rudiments of the third and fourth walking legs (Fig. 6J).

The proboscis is longer than the chelifores and is directed downwards. The basal article of the chelifores is longer than the chelae and carries five dorsodistal spines on the distal part; the immovable finger bears one spine on the outer surface; the fingers are curved at the tip and smooth on the internal surface; slit-like pores are present on the outer lateral surfaces of the chela bases and on the dorsolateral surface of the basal article. 


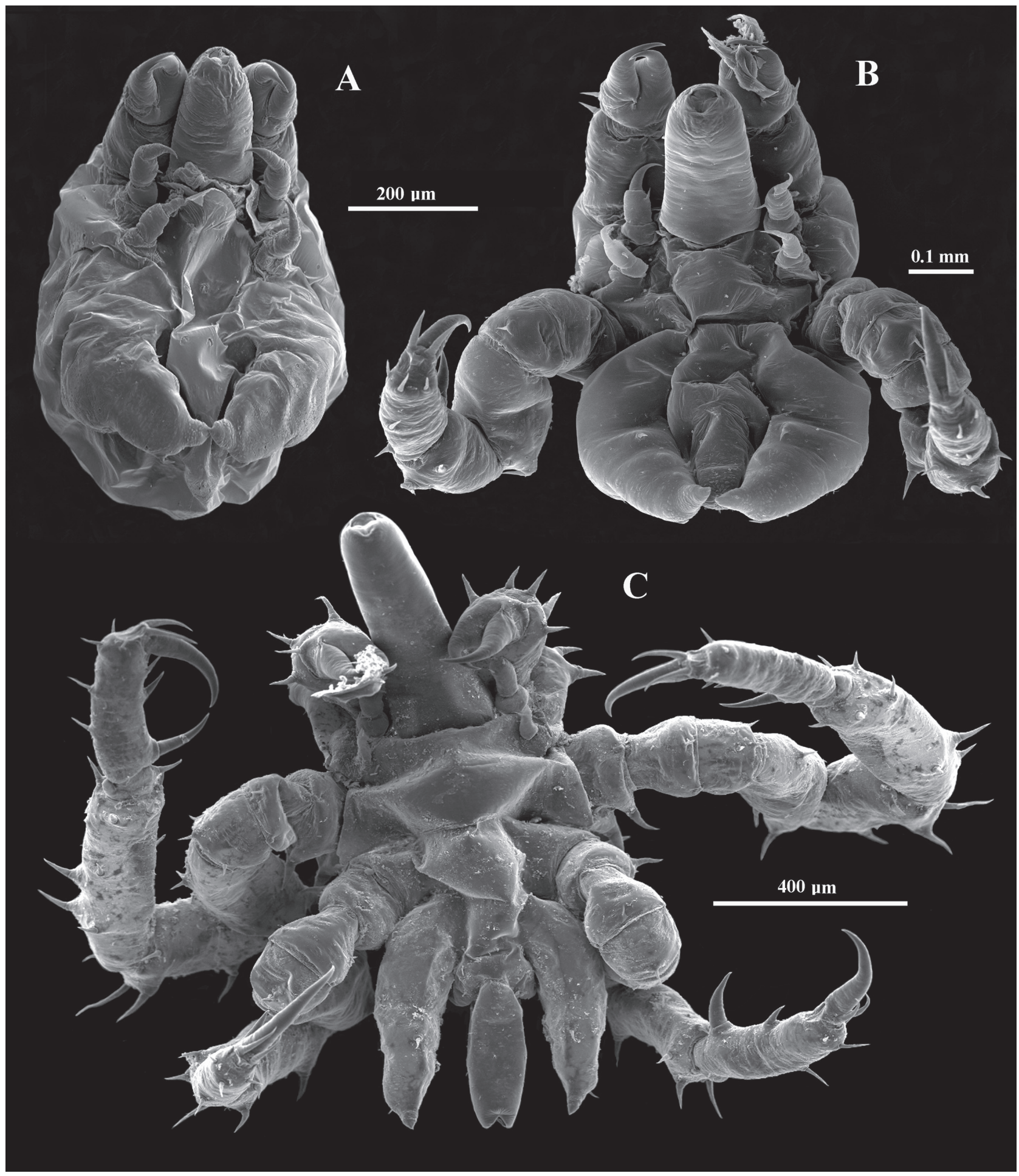

FIG. 4. - Larvae of Ammothea glacialis (Hodgson, 1907). SEM photographs: A, second instar larva, ventral view; B, third instar larva, ventral view; C, fourth instar larva, ventral view.

Pair II of the larval appendages is biarticulated, the basal article with one spine on the internal surface, the distal article with four terminal spines. Pair III of the larval appendages is unarticulated, ending in a point with one subterminal spine.
The first pair of walking legs is longer than in the previous instar, and the number of articles increases to eight. Coxa I with two dorso-distal spines; coxa II with one ventro-distal spine; coxa III with two ventro-distal spines; femur with three dorso-dis- 


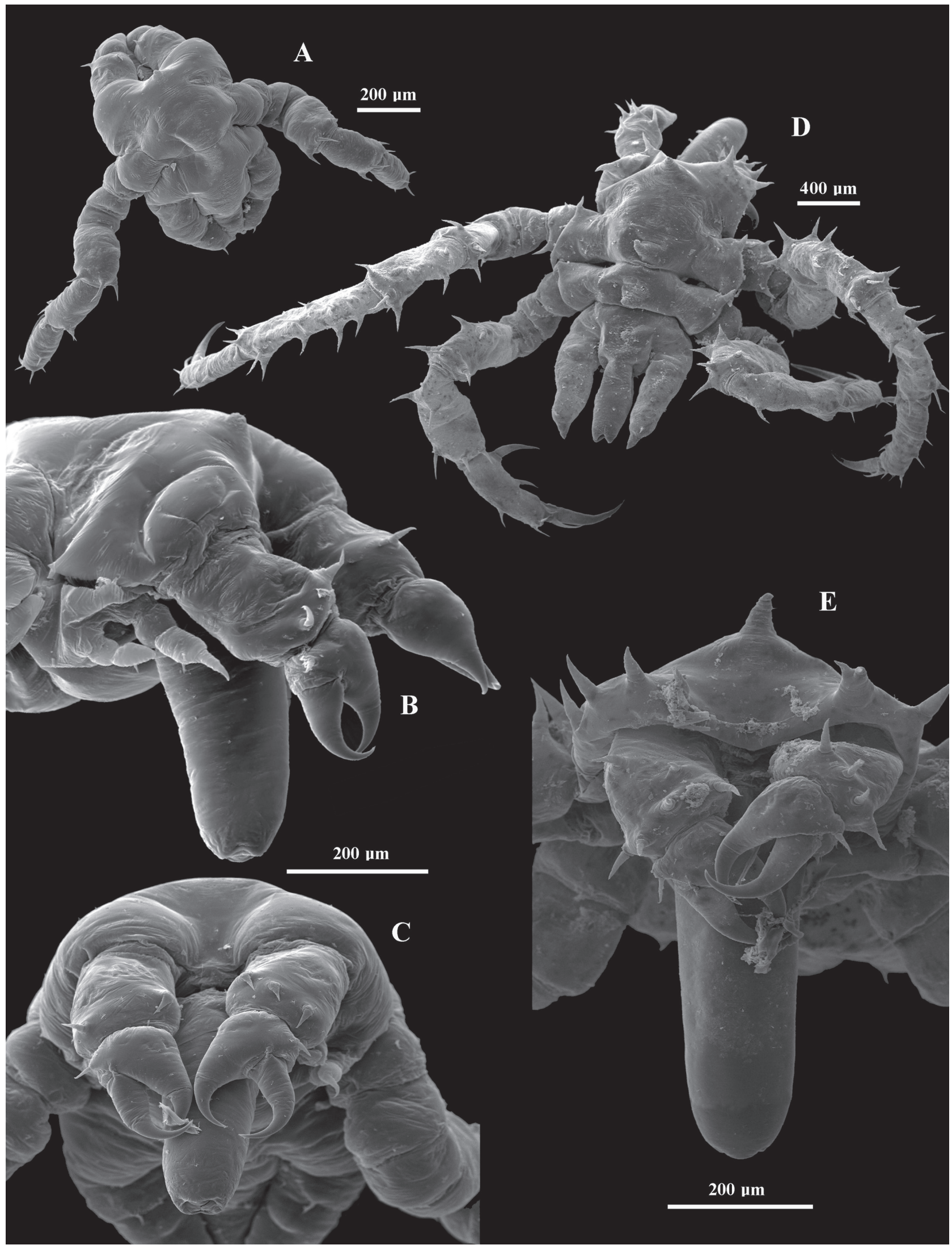

FIG. 5. - Larvae of Ammothea glacialis (Hodgson, 1907). SEM photographs: A, third instar larva, dorsal view; B, third instar larva, laterofrontal view; C, third instar larva, frontal view; D, fourth instar larva, dorsal view; E, fourth instar larva, frontal view. 

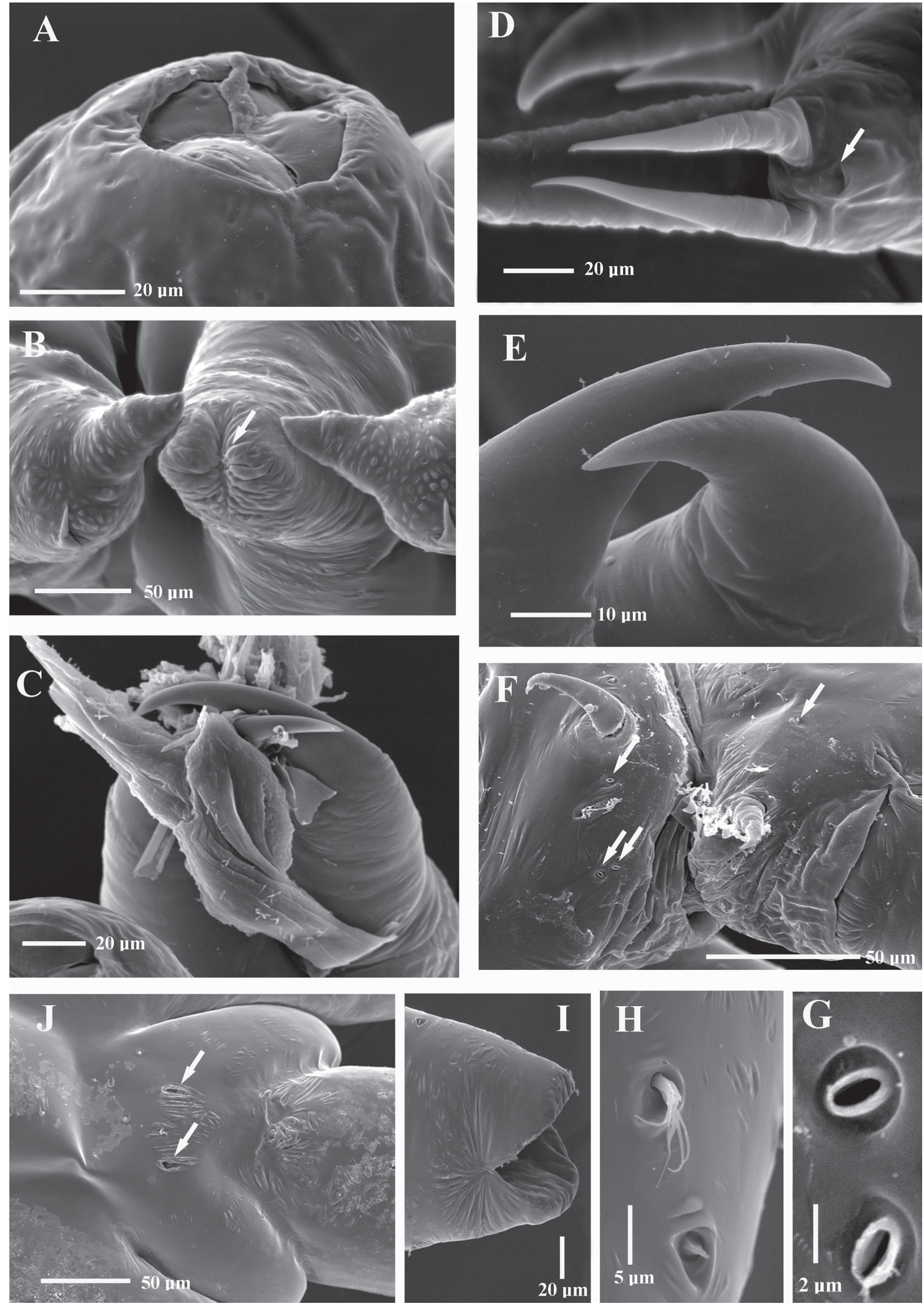

FIG. 6. - Larvae of Ammothea glacialis (Hodgson, 1907). SEM photograph: A, mouth, second instar larva; B, anus, third instar larva; C, attachment to the cohesive ball, third instar larva; D, pore on second walking leg, fourth instar larva; E, fingers of chelifore, internal surface, second instar larva; F, pores on outer lateral surfaces of chela bases and on dorsolateral-distal surface of basal segment (lateral-distal of chelifore basal segment lacks spinning apparatus), third instar larva; G, detail from F showing the pores; H, multifurcated sensillum, fourth instar larva; I, anus, fourth instar larva; J, pores in the centre of the rudiments of the fourth walking legs, fourth instar larva. 
tal spines and one ventro-medial spine; tibia I with three dorso-medial spines, three dorso-distal spines and two short ventro-distal spines; tibia II with eight dorsal spines, one ventro-medial spine and two ventro-distal spines; tarso with one strong ventral spine; propodus with three dorsal spines, two dorso-distal spines, one heel spine more developed than a sole spine, and two ventro-distal spines. Main claw and auxiliary claws are present. A pore of unknown origin or function is located on the propodus close to the auxiliary claw bases (Fig. 6D).

The second pair of walking legs has six articles and is similar to the first pair of the third instar, except for the presence of two dorso-medial spines on femur and tibia I, as well as two latero-distal spines and one medial spine, all three ventrally, on Tibia I.

The limb buds of the third pair of walking legs are similar to the first pair of the second instar, and the second pair of the third instar.

The abdomen is clearly distinguishable, with the anus apparently functional for the first time in the series of larval instars studied in this paper (Fig. 6I).

\section{DISCUSSION}

In the last embryonic phase the embryo differentiates three pairs of larval appendages, with spination, and a proboscis develops around the stomodeum; the embryo becomes a protonymphon larva (Arnaud and Bamber, 1987). This larva has typically an anterior proboscis bearing mouth and three pairs of appendages, a pair of chelifores and two pairs of larval appendages with claw-like terminal articles.

Bain (2003a) proposed four pycnogonid postembryonic developmental pathways, based on the following: the first postembryonic stage; the larvae's way of life; and the order of the initiation of the walking legs. These were named: (1) typical protonymphon; (2) atypical protonymphon; (3) encysted larvae; and (4) attaching larva.

In three of these four proposed variants (first to third), the larvae hatch from the egg as protonymphons and promptly leave the males. However, the following differences in development exist:

(1) In the "typical protonymphon" development during the course of several moults the larval appendages pairs I to III develop to form the definitive chelifores, palps and ovigerous legs, while walking legs are serially budded at the posterior end of the body (Okuda, 1940; Bain, 2003a;
Vilpoux and Waloszek, 2003; Bogomolova and Malakhov, 2003, 2004; Gillespie and Bain, 2006; Bogomolova, 2007).

(2) In the "atypical protonymphon" development the larva acquire all their limb buds at once at the first moult, and the developing appendages gradually acquire a definitive number of articles (Ohshima, 1933; Bain, 2003a).

(3) In the "encysted larva" development the larval II and III appendages disappear during the first moult and inside the host the three pairs of the walking legs are initiated simultaneously while the fourth pair is initiated later on (Staples and Watson, 1987; Bain, 2003a; Bogomolova and Malakhov, 2003; Lovely, 2005).

Bain (2003a) proposed the fourth pattern of development, known as "attaching larva", with information from Nakamura (1981) (based on Propallene longiceps (Böhm, 1879)). It is notable for the fact that in this case the larva remains on the ovigerous legs of the male until the late stages of development. In the first developmental stage the second and third pairs of larval appendages are absent, although the primordia of two pairs of walking legs are present. This is a not feeding larval stage hatching with abundant yolk reserves (Nakamura, 1981; Bain, 2003a, b; Bogomolova and Malakhov, 2003, 2004).

Bogomolova and Malakhov (2006) suggested a fifth pattern of development, the "lecithotrophic protonymphon". This developmental pattern has been revealed from the study of Nymphon grossipes Fabricius 1794. These authors considered that it is a less specialised variant of lecithotrophic development than attaching larva, and the order of the initiation and development of the extremities and abdomen is altered. The first postembryonic stage is a protonymphon with characteristic larval appendages, the larva is proportionally larger than the protonymphon of previously described larval development types and is filled with yolk. The development of walking legs is strictly sequential and the larvae remain on the male's ovigerous legs during a number of moults (Bogomolova and Malakhov, 2003, 2004, 2006; Bogomolova, 2007).

On the other hand, Bamber (2007) considered that pycnogonids have only one type of larva: the protonymphon. The eggs hatch as a protonymphon larva or as a postlarva (the larval stage having been passed in the egg). In this case "attaching larva" must be considered as a postlarva. Bogomolova and Malakov (2003) considered that the early formation 
of the rudiments of walking legs is a manifestation of the tendency toward embryonisation or suppression of early larval stages, which is observed in pycnogonids with the fourth pattern of development proposed by Bain (2003a).

The larvae of pycnogonids have provisional structures for attachment to the cohesive ball or to the host. Their particular morphology and relative degree of development are dependent, basically, on how long the larvae remain on the ovigerous legs of the male and what way of life they have later. These structures are the pairs II-III of larval appendages (the future palps and ovigers) and the spinning apparatus. The latter has been reported with several different names: spinning apparatus (Hoeck, 1881), byssal gland (Meinert, 1899), cheliceral gland (Meglitsch, 1967), and attachment gland (Bain, 2003b). The larvae of pycnogonids have similar morphology and size when they have a similar pattern of development, even in species of different families (Bogomolova and Malakhov, 2003; Bogomolova, 2007).

The larval stages of Ammothea glacialis described in this paper are quite similar to the larval development of Achelia alaskensis (as Ammothea alaskensis in Okuda, 1940). However, in the latter species the larvae leave the male and live in association with the hydromedusae Polyorchis karafutoensis.

The observed larval development of Ammothea glacialis resembles the development described for Nymphon grossipes, except for relatively small II and III appendages and the lack of a silk-spinning spine in the basal segment of the chelifore (Fig. 6F) (see Bogomolova and Malakov, 2006, and Bogomolova, 2007).

Russian scientists related the larger size of Nymphon grossipes larva-in comparison with that of Propallene longiceps - to a more prolonged period on the male's ovigerous legs. The larvae of A. glacialis have a similar size to those of $N$. grossipes. However, it is in the last observed stage (when they are still attached to the cohesive ball) when A. glacialis larvae have two pairs of walking legs and a primordial of the third one (stage IV), while $N$. grossipes larva have completed the development of three walking leg pairs and show a primordial of the fourth one (this form being the last observed one (see Bogomolova and Malakov, 2006, and Bogomolova, 2007)).

The absence of yolk reserves and the functional anus (Fig. 6I) in the last form observed in this study allow us to suppose that the fourth stage of A. glacialis described here may be close to leaving the male's ovigerous legs. In several species with similar features they leave the males, as in Propallene longiceps, Nymphon grossipes and Pseudopallene spinipes (Fabricius, 1870) (Nakamura, 1981; Bogomolova and Malakov, 2003), while in other species the larvae remain on the male's body but not on the legs, as Bouvier (1923) commented for Boreonymphon robustum (Bell, 1855).

Bogomolova and Malakhov (2004) and Bogomolova (2007) also indicated that if a large larva is developing on the appendages of a male for a long time, the function of attachment mostly passes from larval appendages II and III to the spinning apparatus (a similar form for $N$. grossipes and Propallene longiceps). But in A. glacialis larvae the spinning apparatus is absent (Fig. 6F), and the attachment to the cohesive ball is assumed by the chelifores (Fig. 6C).

In the family Ammotheidae different patterns of development (typical protonymphon, atypical protonymphon, and encysted larva) or postlarva have been described. However, the initial phases of development on the ovigerous legs of males have not previously been described for this family. This presence of different patterns of development-with their associated morphological differences-in a particular family may turn out to be heavily influenced by ecological factors (Bain, 2003a; Bamber, 2007).

\section{ACKNOWLEDGEMENTS}

The authors wish to thank the officers and crew and many colleagues for their help on board during the VLT-2004 (Italica, XIX Spedizione) cruise. We take this opportunity to extend our thanks to the cruise leader and steering committee of the cruise, especially Riccardo Cattaneo, Maria Chiara Chiantore and Roberto Meloni, who kindly facilitated the work on board and provided the opportunity to collaborate in this Antarctic programme. Support for this work was provided by the Spanish CICYT project CGL2004-20062-E.

\section{REFERENCES}

Arnaud, F. and R. Bamber. - 1987. The Biology of Pycnogonida. Adv. Mar. Biol., 24: 1-96.

Bain, B.A. - 2003a. Larval Types and a Summary of Postembryonic Development within the Pycnogonids. Invert. Reprod. Dev., 43: 193-222.

Bain, B.A. - 2003b. Postembryonic Development in the Pycnogonid Austropallene cornigera (Family Callipallenidae). Invert. 
Reprod Dev., 43: 181-192.

Bain, A.B. and F.G. Govedich. - 2004 Courtship and mating behavior in the Pycnogonida (Chelicerata: Class Pycnogonida): a summary. Invert. Reprod. Dev., 43: 63-79.

Bamber, R.N. - 2007. A holistic re-interpretation of the phylogeny of the Pycnogonida Latreille, 1810 (Arthropoda). Zootaxa, 1668: 295-312.

Bogomolova, E.V. - 2007. Larvae of three sea spider species of the genus Nymphon (Arthropoda: Pycnogonida) from the White Sea. Russ. J. Mar. Biol., 33: 145-160.

Bogomolova, E.V. and V.V. Malakhov. - 2003. Larvae of sea spiders (Arthropoda, Pycnogonida) of the White Sea. Zool. Zhurn., 82: 1-17.

Bogomolova, E.V. and V.V. Malakhov. - 2004. Fine morphology of sea spider larvae (Arthropoda, Pycnogonida) of the White Sea. Zool. Bespozvonochnykh, 1: 3-28.

Bogomolova, E.V. and V.V. Malakhov. - 2006. Lecithotrophic protonymphon is a special type of postembryonic development of sea spiders (Arthropoda, Pycnogonida). Dokl. Biol. Sci., 409: 328-331.

Bouvier, E.L. - 1923. Fauna de France 7. Pycnogonides. Fédération Française des Sociétés de Sciences Naturelles Office Central de Faunistique. Paris.

Cano, E. and P.J. López-González. - 2007a. Colossendeis species (Pycnogonida: Colossendeidae) collected during the Italica XIX cruise to Victoria Land (Antarctica), with remarks on some taxonomic characters of the ovigers. Sci. Mar., 71(4): 661-681.

Cano, E. and P.J. López-González. - 2007b. Ammotheidae (Arthropoda: Pycnogonida) collected during the Victoria Land Transect cruise 2004 (Ross Sea, Antarctica), with a description of a new species of Ammothea. Mar. Biol. Res., 3: 438-445.

Gillespie, J.M. and B.A. Bain. - 2006. Postembryonic development of Tanystylum bealensis (Pycnogonida, Ammotheidae) from Barkley Sound, British Columbia, Canada. J. Morphol., 267: 308-317.

Hedgpeth, J.W. - 1947. On the evolutionary significance of the Pyc- nogonida. Smithson. Misc. Collect., 106:1-54.

Hoek, P.P.C. - 1881. Report on the Pycnogonida dredged by HMS Challenger 1873-1876. Rep. Sci. Res. Exploring Voyage of HMS Challenger, 3(10): 1-167.

Lovely, E.C. - 2005. The life history of Phoxichilidium tubulariae (Pycnogonida; Phoxichilidiidae). Northeast Nat., 12: 77-92.

Mahon, A.R., Arango, C.P. and Halanych, K.M. - 2008. Genetic diversity of Nymphon (Arthropoda: Pycnogonida: Nymphonidae) along the Antarctic Peninsula with a focus on Nymphon australe Hodgson 1902. Mar. Biol., 155: 315-323

Meglitsch, P.A. - 1967. Invertebrate Zoology. Oxford University Press, New York.

Meinert, F. - 1899. Pycnogonida. The Danish Ingolf-Expedition, 3: $1-71$.

Nakamura, K. - 1981. Post-embryonic development of a pycnogonid, Propallene longiceps. J. Nat. Hist., 15: 49-62.

Ohshima, H. - 1933. Young pycnogonids found parasitic on nudibranchs. Annot. Zool. Japon., 14: 61-66.

Okuda, S. - 1940. Metamorphosis of a pycnogonid parasitic in a hydromedusa. J. Fac. Sci. Hokkaido Imperial Univ. Zool., 7: 73-86.

Staples, D.A. and J.E. Watson. - 1987. Associations between pycnogonids and hydroids. In: J. Bouillion (ed.), Modern Trends in the Systematics, Ecology, and Evolution of Hydroids and Hydromedusa, pp. 215-226. Oxford University Press.

Vilpoux, K. and D. Waloszek. - 2003. Larval development and morphogenesis of the sea spider Pycnogonum litorale (Ström, 1762 ) and the tagmosis of the body of Pantopoda. Arthropod Struct. Dev., 32: 349-383.

Wilhelm, E., D. Bückmann and K.H. Tomaschko. - 1997. Life cycle and population dynamics of Pycnogonum litorale (Pycnogonida) in a natural habitat. Mar. Biol., 129: 601-606.

Scient. ed.: M.P. Olivar.

Received July 8, 2008. Accepted December 18, 2008.

Published online April 27, 2009. 